${ }^{I}$ Fundação Getúlio Vargas, Centro de Pesquisa e

Documentação de História Contemporânea do Brasil

(FGV-RJ/CPDOC), Brasil

lucia.lippi65@gmail.com

Lucia Lippi Oliveira'

\title{
MANUEL BONFIM: AUTOR ESQUECIDO OU FORA DO TEMPO?
}

Parto da concepção de que analisar a recepção da obra de um autor envolve circunscrevê-la no tempo e no espaço. É o que vou tentar fazer aqui a propósito de Manuel José do Bonfim tomando principalmente sua obra América Latina: males de origem, publicada em I905. Quero acompanhar como Manuel Bonfim tem sido lido desde que lançou seu primeiro livro e procurar entender como seu esquecimento tem sido interpretado. ${ }^{\mathrm{I}}$

Manuel Bonfim nasceu em Sergipe em I 868 e morreu no Rio de Janeiro em I932. Filho de um bem-sucedido comerciante de Aracaju, seu universo não era aquele da casa-grande açucareira como foi comum a outros intelectuais e literatos pertencentes à elite nordestina. Vai estudar medicina em Salvador e se muda em I 888 para o Rio, onde se forma pela Faculdade de Medicina do Rio de Janeiro. Na capital da República atuou como jornalista, professor e diretor do Instituto de Educação, além de ocupar outros cargos no campo da educação; foi também deputado federal por Sergipe. Em I902, vai estudar psicologia experimental em Paris, onde fica por oito meses. Lá escreveu A América Latina: males de origem, publicado em I905. Além desse livro inaugural, vamos aqui mencionar outras obras, tais como: O Brasil na América: caracterização da formação brasileira (I929); O Brasil na história: deturpação dos trabalhos, degradação política (I930); O Brasil nação: realidade da soberania brasileira (I93I). E principalmente vamos registrar a recepção que tais obras tiveram e discutir o "esquecimento" que teria acompanhado o autor. 
Para avançar na análise da obra de um autor é preciso mencionar os temas abordados, as teses apresentadas, as explicações, o tipo de argumentação e os conceitos usados. E também o tipo de retórica usada para demonstrar uma tese, divulgar suas ideias ou convencer/converter seus leitores. Assim como é necessário conhecer a obra, é igualmente relevante conhecer o autor, ou seja, saber quem fala. Aqui os dados biográficos são importantes para nos informar que posição ele ocupa na estrutura social. Por fim, deve-se dar atenção à posição ocupada pelo autor no campo intelectual de sua época. Ou seja, onde estudou? Quais foram seus contemporâneos? Quem pertence à mesma geração? De quais instituições fez parte? Com quem polemizou ou divergiu? Quem o resenhou? Assim, é preciso examinar a teia de relações para levar adiante a análise sociológica de uma obra e de seu autor.

Todos esses elementos nos ajudam a entender o sucesso ou o esquecimento de um autor ou de uma obra para além do possível valor intrínseco de seu conteúdo. Estou querendo ressaltar que a recepção, a aceitação ou o reconhecimento de um autor depende não só das qualidades de suas ideias e de seu texto, mas também de variáveis relacionadas ao campo intelectual existente e do qual o autor faz parte. Assim, quando acompanhamos a recepção da obra ou do autor, temos também que prestar atenção em quem a edita ou reedita, quem faz a crítica da obra, quem a cita em seus textos, quem escreve prefácios e introduções.

Vale também lembrar que o processo de recepção de uma obra não segue uma linha reta e sem oscilações. Autores muito reconhecidos em um tempo podem ser esquecidos ou rejeitados em outro momento. Autores e seus temas fazem parte de um jogo de lembranças e esquecimentos que caracteriza tanto a construção da memória quanto um panteão de autores relevantes do pensamento social. E, é bom lembrar, isso vale para todos, tanto para autores ilustres quanto para desconhecidos. Já fiz um ensaio explorando a fortuna crítica de Oliveira Vianna, autor que oscila entre ser esquecido e lembrado, e mais, quando lembrado o é ora valorizado positivamente, ora negativamente (Oliveira, I993). Gilberto Freyre também teve recepção altamente elogiosa quando publicou Casa-grande \& senzala nos anos I930, padeceu de rejeição e esquecimento nos anos I960 e foi novamente recuperado a partir dos anos I980.

\section{PARA COMEÇAR...}

Gostaria de mencionar que fui apresentada a Manuel Bonfim pelo livro de Flora Süssekind e Roberto Romano, História e dependência: cultura e sociedade em Manuel Bonfim (I984). Ali os autores escrevem uma importante introdução ao autor, além de publicar uma seleção de trechos de sua obra contemplando os temas centrais presentes nos livros de Bonfim. Estava à época pesquisando autores que pensaram a questão nacional ao longo da Primeira República, tema 
de minha tese de doutorado que veio a ser publicada em livro (I990). Ele e muitos outros intelectuais estavam completamente esquecidos, eram os grandes ausentes dos programas dos cursos de pós-graduação no Brasil nos anos I980.

O livro de Aluizio Alves Filho (I979) e o artigo de Darcy Ribeiro (I984) expressam e sinalizam exatamente o silêncio em torno de Manuel Bonfim que marcava os anos I970 e I980. Para Alves Filho, a omissão teria a ver com a própria reflexão de Bonfim, que se centrava no povo e não na elite. Darcy Ribeiro, por outro lado, vai destacar a originalidade de seu pensamento que estaria muito à frente do que aqui se escrevia sobre o país, principalmente se olharmos seu livro sobre a América Latina. A leitura de Darcy Ribeiro a respeito de Bonfim pode ser relacionada ao processo de redemocratização que se operou nos diversos países da América Latina, após décadas de ditadura. Um dos pontos muito debatidos à época foi o peso da dívida externa contraída pelo Brasil, e que estaria na base das dificuldades do país. Nessa linha interpretativa o capital estrangeiro seria um "parasita" a sugar a energia brasileira. É preciso igualmente lembrar que Darcy Ribeiro vai ser vice-governador de Leonel Brizola, político que sempre batia na tecla das "perdas internacionais".

Manuel Bonfim foi também abordado em tese de doutorado de Ronaldo Conde Aguiar na Universidade de Brasília (UnB), publicada em 2000. O autor vem sendo abordado em dissertações de mestrado e em artigos publicados em revistas acadêmicas a partir dos anos 1990 . Pode-se indagar se parte dessa recuperação atual das obras de Bonfim teve lugar a partir das reedições de seus livros pela Editora Topbooks. Essa mesma editora publicou em livro o trabalho mencionado de Ronaldo Conde Aguiar, que trata da trajetória biográfica de Bonfim. Aguiar é também quem escreve a Introdução à reedição de $O$ Brasil nação (I996).

José Mário Pereira, editor da Topbooks, esclarece que teve "a curiosidade despertada pela obra do Manuel Bonfim primeiro por um livrinho editado pela Achiamé [Pensamento político no Brasil: Manoel Bomfim, um ensaísta esquecido, de Aluizio Alves Filho] e depois, trabalhando com Darcy Ribeiro, ele voltou a me falar desse com entusiasmo, sugerindo que lesse A América Latina, males de origem". E continua:

Quando comecei a editora tratei logo de editá-lo, com prefácio do Darcy (na verdade um ensaio que ele antes publicara na Revista do Brasil), e orelhas assinadas pelo dr. Evaristo de Moraes Filho.

Essa minha edição provocou muito interesse, dado que significou a volta do Bonfim às livrarias e ao sistema intelectual.

A seguir publiquei O Brasil nação, e O Brasil na América.

Agora está saindo aqui $O$ Brasil na história, esgotado há mais de 70 anos.

Também publiquei a biografia de Bonfim, Manuel Bonfim, o rebelde esquecido, de Ronaldo Conde Aguiar (Informações fornecidas pelo editor por e-mail em Io/7/2013).

Se ele foi esquecido durante muito tempo, é possível dizer que hoje isso não parece mais ser verdade. Bonfim vem sendo mencionado e estudado 
em obras recentes que objetivam construir um painel, um panteão de obras e autores que explicam o Brasil. Lembro que o livro Introdução ao Brasil: um banquete no trópico (200I), organizado por Lourenço Dantas Mota, traz um texto de Roberto Ventura sobre Bonfim. O historiador José Carlos Reis, na obra As identidades do Brasil 2 (2006), dedica um capítulo ao nosso autor. Outro livro que apresenta um panorama de obras significativas, intitulado Um enigma chamado Brasil (2009), organizado por André Botelho e Lilia Moritz Schwarcz, traz importante texto de André Botelho, autor que trabalhou sobre Bonfim em seu livro Aprendizado do Brasil: a nação em busca dos seus portadores sociais (2002).

Coroando essa listagem de obras que recuperam Manuel Bonfim, pode-se citar que, por ocasião dos 500 anos de Descobrimento do Brasil, o autor passa a fazer parte do panteão de autores nacionais organizado por Silviano Santiago, ao incluir o seu livro A América Latina, com introdução de Flora Süssekind, no volume Intérpretes do Brasil (2000).

\section{OS MALES DE ORIGEM}

Com a ressalva mencionada, ou seja, de que ele não se encontra tão esquecido nos dias de hoje quanto parecia estar nos anos I980, vamos tomar ainda como guia deste artigo a premissa de que o esquecimento do autor não faria jus à qualidade e relevância de sua obra. Assim, cabe perguntar: por que foi esquecido? Que lugar ocupou no campo intelectual de seu tempo? Quais foram seus temas?

Nascido em I 868 em Sergipe, como já foi mencionado, veio para o Rio de Janeiro, onde se formou como médico. Situado no contexto do fim do Império e início da República, ele fazia parte do grupo geracional que à época rejeitava os cânones de uma tradição e adotava princípios considerados científicos para entender e corrigir o país. Partindo do campo da medicina, ele se torna um autor escrevendo sobre o Brasil, tentando explicar o atraso do país. Se isto é comum a muitos intelectuais republicanos, a partir daí começa a se delinear uma diferença específica de Manuel Bonfim em relação a seus pares, igualmente compromissados com a tarefa de salvar o país.

No primeiro contexto no qual ele escreve - o fim do século XIX e início do XX, a mudança do Império para a República -, como se explicava o atraso do país? Engenheiros, médicos e educadores compõem as principais categoriais de uma nova elite que examinou os males do Brasil na virada do século XIX para o XX e produziu seus diagnósticos. Entre eles, o discurso médico ganhou grande destaque ao propor "higienizar e educar" como caminhos para tirar o país do atraso. Assim, a ideia de que é necessário produzir diagnósticos e prognósticos torna-se muito comum. Os procedimentos da medicina extravasam o campo médico e vão aparecer nos ensaios políticos que buscam dar sugestões para se alcançar o progresso, para se fazer parte do mundo civilizado. 
Desse modo, o vocabulário médico invade outros campos, inclusive a literatura (Herschmann, I996).

As elites no Brasil de então desejavam que o país estabelecesse uma sintonia com países da Europa. Para reformar a sociedade entendia-se ser necessário substituir o romantismo pelo naturalismo, desenvolver um saber secular, "científico", capaz de desvendar a natureza tropical e as raças formadoras do Brasil. A natureza tropical deixa de ser apenas uma inspiração (como no Romantismo) e passa a ser princípio central de explicação da nação. O Brasil se apresenta como um enigma a ser decifrado já que a ciência da época considerava a impossibilidade de se construir uma civilização nos trópicos.

Além do clima, a raça era mobilizada para explicar a indolência do brasileiro e a incapacidade de se alcançar o progresso. Muitos diagnósticos registram a mestiçagem como uma bagagem a ser vencida para que fosse possível superar o atraso. Muitos aceitam como solução a imigração europeia, vista como capaz de minimizar a "fatalidade da inferioridade" racial do país. Daí a tese do "branqueamento" para fundamentar a vinda de mais brancos como caminho para, mediante a mestiçagem, exatamente "embranquecer" o povo brasileiro.

O papel e a atuação dos médicos na capital da República são objeto da dissertação de mestrado de Micael Herschmann (I996). Observa ele que, ao medicalizar a sociedade brasileira, a medicina diversifica sua atuação e vai criar diversas especializações tais como Criminologia, Medicina Legal, Higiene, Saúde e Psicologia, que se fazem presentes nas duas instituições de formação médica existentes no país. Na Faculdade de Medicina do Rio de Janeiro predomina a atuação, sob influência francesa, de combate às doenças (epidemias) atentando para o fator do clima. Ali Oswaldo Cruz foi um pioneiro no desenvolvimento da Saúde Pública e Higiene, e Miguel Couto (I865-I934) foi, por assim dizer, um herdeiro dessa linha de investigação. A Faculdade da Bahia, por outro lado, torna-se campo experimental para patologia e bacteriologia, prevalecendo uma orientação alemã e italiana. Essa Escola teve Nina Rodrigues como figura exponencial e nela se prestou atenção ao doente e às características transmissíveis de forma hereditária. Foi ali que mais se desenvolveu o campo da Medicina Legal. A chamada Escola Nina Rodrigues teve como discípulos Afrânio Peixoto e Arthur Ramos, este último figura fundamental que a tornou conhecida e reconhecida como matriz da antropologia no Brasil (Corrêa, 200I; Schwarcz, I993).

Para além da diferenciação entre escolas e linhas de investigação da medicina, o ideário moderno foi assumido pelos "homens de ciência" tornando a medicina um modelo a ser seguido por todos aqueles que queriam transformar a sociedade. Retornando ao ponto central: tanto cientistas quanto literatos passam a fundamentar seus discursos em princípios da ciência. E os cientistas do campo da medicina se voltam para uma atuação no mundo social. Assim os 
médicos se organizam institucionalmente e constroem sua identidade como "missionários do progresso".

Como solucionar os problemas nacionais? Como curar os "males do país"? Diante do diagnóstico de insalubridade, ignorância, atraso da sociedade, produzem-se prognósticos voltados para regenerar a sociedade, encontrar remédios para o corpo e o espírito, impedir a proliferação de "casos patogênicos" que ameaçavam o "organismo social".

Os médicos como "missionários do progresso" vão oferecer ao Estado um novo caminho para o país chegar ao mundo civilizado. O Estado republicano, tendo à sua disposição tais missionários, declara o fim da autonomia da família e vai tentar estabelecer normas para a sociedade aumentando o controle social. Tudo isto se faz vinculado às ideias racistas e evolucionistas, consideradas científicas. Intervir, curar, sanear, educar, ou melhor, educar e higienizar resumem as principais metas para resolver a situação de ignorância na qual se encontrava o povo brasileiro e erradicar as epidemias que contribuíam para desmoralizar a capital da República perante as capitais europeias. A Campanha da Vacina Obrigatória e a chamada Revolta da Vacina na capital da República exemplificam um momento intenso e tenso dessa relação entre medicina, governo e povo.

É neste contexto que Bonfim aborda as causas do atraso assumindo um procedimento similar ao adotado pelo médico ao examinar seu paciente: ele precisa conhecer o passado do paciente (anamnese) para chegar a um diagnóstico e poder estabelecer o tratamento (Ventura, 200I). Escreveu A América Latina enquanto estava em Paris estudando psicologia, para onde foi em $1902 \mathrm{em}$ uma espécie de exílio, fazendo um caminho típico do intelectual de país dependente que lá fora "pode descobrir a si mesmo, como um outro, até mesmo bárbaro" (Botelho, 2002: 69). O livro teria como motivação uma reação à visão negativa que europeus tinham da América do Sul e que pode ser exemplificada por Arthur de Gobineau, representante francês no Brasil e correspondente de D. Pedro II, para quem a população do país era totalmente mulata, viciada no sangue e no espírito.

Manuel Bonfim vai então publicar esse seu primeiro livro A América latina: os males de origem em I905 pela editora Garnier. Ele pode ser considerado seu livro mais importante e mais polêmico, já que ali ele se contrapõe às explicações hegemônicas daquela época, que atribuíam os males do Brasil e dos países da América Latina às raças inferiores, às populações mestiças e ao clima tropical. Bonfim, como diz Roberto Ventura (200I), ao contrário, vai falar da exploração das colônias pelas metrópoles e dos escravos pelos senhores. E faz isso recorrendo a uma noção tirada da biologia: o parasitismo. Nesta obra combate o racismo, o evolucionismo e o positivismo. Vai contra a explicação racial em voga, contra a hierarquia entre as raças que, segundo ele, servia para justificar o domínio dos fracos pelos fortes. Ataca ideias e visões consideradas 
científicas à época e que se faziam presentes de diferentes modos em autores importantes como Silvio Romero, Nina Rodrigues e Euclides da Cunha.

Citei esses três autores só para deixar claro contra quem Bonfim estava se posicionando. Talvez isso possa nos ajudar a entender por que nos livros, artigos sobre intelectuais, instituições e cientistas das gerações do fim do século XIX e início do XX Bonfim não é citado.

Silvio Romero recusa as explicações, as teses de Bonfim. Ele escreve 25 artigos, que depois foram reunidos no livro A América Latina: análise do livro de igual título do dr. Manoel Bonfim (I906), contestando Bonfim. Tais artigos são considerados de pouco valor, já que se dedicam a desacreditar as qualidades intelectuais de Bonfim. O livro-resposta de Silvio Romero serve para demonstrar que o livro A América Latina não passou em branco. Esse livro-resposta com comentários em estilo polêmico e violento de Silvio Romero ataca a obra de Bonfim considerando-a cheia de erros, malfeita e falsa. Silvio Romero ataca também o que nomeia como "socialismo de colegial" e "reacionarismo negris ta e caboclizante contra as raças superiores". Mas esse tipo de comentário, é bom que se note, não alterou a fama de Silvio Romero. Ele é considerado figura fundadora do campo literário ao escrever sua história da literatura no Brasil. Seu papel e sua relevância são reforçados com o passar do tempo. Isso pode ser percebido quando Antonio Candido, outra figura-chave do campo da literatura, toma Silvio Romero como objeto central de um dos seus primeiros livros (Candido, I988). Nina Rodrigues, valorizado por Afrânio Peixoto e por Arthur Ramos, é considerado pai da antropologia brasileira (Corrêa, 200I). E, por fim, Euclides da Cunha, um dos heróis do pensamento brasileiro, cuja obra Os sertões, publicada em I902, causou impacto marcante e cujo autor foi considerado, por figuras como Alceu Amoroso Lima, o fundador de um tipo de explicação sociológica do Brasil.

Bonfim, como já foi mencionado, produz um discurso antirracista contra a corrente dominante à época e pretende explicar os males da América Latina por meio da exploração das colônias pelas metrópoles. Ao mesmo tempo produz um discurso antiamericano: atacou o imperialismo dos Estados Unidos, também contra uma corrente pan-americanista que procurava escapar da influência política europeia e da qual faziam parte Rio Branco, Rui Barbosa, Joaquim Nabuco e até Silvio Romero, que valoriza a atuação política norte-americana já que essa permite proteção diante do perigo alemão representado no Brasil pelas colônias do Sul do país.

Neste sentido, Bonfim poderia ser aproximado de Eduardo Prado em seu antiamericanismo. Aproximação, entretanto, limitada já que eles diferiam em suas análises do passado colonial. Prado valoriza o passado português enquanto Bonfim o recusa. O antiamericanismo de Eduardo Prado em A ilusão americana (1893) diferencia não só o Brasil dos Estados Unidos, mas também o Brasil dos países ibéricos que optaram pelo regime republicano no processo 
de independência. Para Prado, o Brasil tinha tido um desenvolvimento peculiar com a monarquia e não deveria copiar as instituições norte-americanas, como fizeram os países hispânicos da América, e que estavam sendo transplantadas pela República para o Brasil (Oliveira, I999).

O antiamericanismo, é bom que se diga, tem longa duração no pensamento social e na cultura brasileira. Ele se mantém ao longo do século XX e, de tempos em tempos, retorna tomando princípios advindos de razões econômicas (anticapitalismo), razões políticas (anti-imperialismo) e razões culturais (antiprotestantismo). O nacionalismo no Brasil está quase sempre tangenciando tais razões. Assim, o nacionalismo e o antiamericanismo de Bonfim têm oferecido razões suficientes para várias de suas redescobertas.

O antilusitanismo teve destaque no passado com a proclamação da República no Brasil e a crise dos primeiros anos do regime republicano na virada do século, quando a colonização portuguesa passa a ser rejeitada como responsável pelo atraso do país. O português é identificado como colonizador e explorador da população brasileira e passa a ser atacado principalmente na capital da República. Assim, a visão de Bonfim encontra aceitação e pode ser aproximada no campo da literatura a Lima Barreto, quando este desenha o nacionalismo de seu personagem no livro O triste fim de Policarpo Quaresma.

A discussão sobre os males, as deficiências, o atraso da nação brasileira, que se acirra na virada do século, ganha novamente força em torno dos anos da Primeira Guerra Mundial, quando a condenação da colonização portuguesa retorna. Ela é vista como um dos problemas do país, já que foi sob o domínio português que se implantaram tanto a escravidão quanto a intolerância para com os descendentes mestiços. Tal interpretação se faz presente, por exemplo, na obra A política no Brasil ou o nacionalismo radical, de Álvaro Bomilcar (I920), autor que vai ter importância para um pensamento católico nacionalista no Brasil. Nessa mesma época, por outro lado, o francófilo Olavo Bilac reafirma a positividade da herança do mundo português e reforça o valor da lusitanidade e da latinidade, das quais o Brasil faz parte por ter sido colonizado pelos portugueses.

$\mathrm{O}$ antirracismo, o antiamericanismo, o nacionalismo de Manuel Bonfim (e sua posição em relação à colonização portuguesa) o colocam como figura disponível a ser acessada ora por um pensamento de direita como no integralismo, ora pela esquerda que o vê como um socialista.

Entre os comentaristas do autor, certamente Flora Süssekind e Roberto Ventura (I984) inauguram um novo patamar ao colocar Manuel Bonfim no espaço da análise e do debate acadêmico. Ao mesmo tempo interpretam a posição de esquecimento do autor na história intelectual brasileira como resultante de uma ambiguidade, já que ele "move-se entre uma linguagem velha e uma ideologia nova". A apresentação aos textos de Bonfim é intitulada "Uma teoria biológica da mais-valia?", ou seja, para os autores Bonfim explica a produção e apropriação do valor do trabalho no nível interno das relações 
entre classes e no nível internacional pelas relações de dependência entre colônias e metrópoles. O parasitismo é como que uma causa primeira, já que produz exploração predatória e gosto pela vida sedentária, é um mal que se abate sobre explorador e sobre explorado, é, assim, causa da decadência e da degradação. Esta perspectiva "marxista" do autor foi apresentada usando conceito biológico em sua análise histórica, embora Bonfim refutasse a homologia entre biologia, zoologia e sociologia.

Süssekind e Ventura voltam a analisar Bonfim em artigos posteriores centrados na obra A América Latina. Ventura (200I) retorna ao tema ao tratar o parasitismo, conceito da botânica e da biologia que Bonfim adapta às relações sociais, e que permite analisar a apropriação de riquezas produzidas pelos índios e africanos. Os parasitas na colonização foram o clero e os agentes da administração colonial. Bonfim criticou também o Estado brasileiro, considerou a vida política republicana uma democracia de fachada, servindo para perpetuar o poder das elites. Para combater e vencer os males do país, Bonfim vai propor um programa de educação, a instrução popular. Isso faz Ventura compará-lo à figura do argentino Domingos Sarmiento em seu livro Educação popular. Vale notar, entretanto, que Sarmiento não foi somente um intelectual, mas foi também um político que na presidência da República derrotou o caudilhismo das províncias argentinas e instalou a educação pública como política de Estado.

Flora Süssekind (2002) também vai retomar Bonfim destacando a importância do livro A América latina: males de origem como forjador de uma consciência latino-americana. Süssekind continua fazendo uma aproximação de Manuel Bonfim com outros autores que na mesma época estão refletindo sobre o continente sul-americano em sua história colonial, sua independência e construção do Estado nacional. O uruguaio José Enrique Rodó e o cubano José Martí estão entre aqueles que também enfatizam as tensões entre os Estados Unidos e a América Latina e criticam o pan-americanismo e a chamada "Doutrina Monroe".

A reflexão de Bonfim sobre a mistura das raças e o elogio da mestiçagem configura uma certa "utopia híbrida" que está presente também no mexicano José Vasconcelos (La raza cósmica, I925) e mais tarde marcará a obra de Gilberto Freyre. Flora Süssekind aponta um diálogo direto de Freyre com Bonfim que pode ser acompanhado pelas referências ao autor em Casa-grande \& senzala. Nesta obra, é preciso lembrar, Freyre também aciona outros autores tais como Alberto Torres, Oliveira Vianna e Azevedo Amaral para diferenciar, dialogar e explicar seus argumentos.

A reprodução do modelo parasitário, segundo Bonfim, se faz presente mesmo com mudanças do regime político de monárquico para republicano. As classes dirigentes se encarregam de impedir que as coisas se transformem. Tais classes seriam compostas por aqueles que, uma vez no poder, impedem quaisquer reformas significativas. Como isso pode ser rompido? Esta é a pergunta de Manuel Bonfim. Aí vai entrar a pedagogia para educar os parasitados, 
o povo. A instrução popular é apresentada como caminho para solucionar tal impasse. Entre a hereditariedade que determina inferioridades inabaláveis segundo as leis da natureza e a educação capaz de alterar tais leis, Bonfim fica com a educação. Até aqui é a educação que alavanca a mudança social.

Só a partir de O Brasil nação, de I928 e publicado em I93I, é que Manuel Bonfim vai mencionar outro remédio, uma revolução. Uma revolução que, segundo Flora Süssekind, deveria ser contra a classe dirigente, quando a conquista do poder seria realizada por uma nova classe que nunca o ocupara e que seria capaz de impor um novo padrão de valores. Vale lembrar que o livro de Sergio Buarque, Raízes do Brasil (1936), também traz um último capítulo sobre a revolução necessária para que país rompa os males de seu passado.

\section{A JORNADA EDUCATIVA OU “UMA ILHA DE LETRADOS NUM MAR DE ANALFABETOS"}

A reflexão erudita de Manuel Bonfim a respeito da história e da política da América Latina e do Brasil, em conflito com seus pares intelectuais na virada do século, não o faz abandonar uma visão missionária, só que agora ela se explicitará no espaço da educação, da pedagogia. Podemos dizer que, depois desse enfrentamento com sua geração, Bonfim, que já tinha abandonado o campo estrito da medicina migrando para a psicologia, vai dar uma trégua na escrita de livros interpretativos sobre o continente e o Brasil. Ou melhor, pelo menos até o fim dos anos I920, várias de suas obras, como Lições de pedagogia: teoria e prática da educação (s/d) e Noções de psicologia (I9I7), abordam o campo que julgava possível resolver os males do Brasil: a educação. Assim ele vai continuar sua militância, só que no campo da educação. Vai se somar a outros intelectuais que apostam na educação e que vão compor uma geração de educadores que comunga da ideia de que sem ensino, sem escola de qualidade, não existe república nem nação.

Assim, uma das soluções para sanar os males do Brasil leva a um amplo projeto pedagógico que ocupa grande espaço durante a Primeira República. O analfabetismo reinante no país na segunda metade do século XIX (cerca de $80 \%$ ) torna a ação da elite letrada muito limitada. A Carta de I89I, ao restringir o voto do analfabeto, consagrou a exclusão política de extensas camadas populares do exercício democrático. Por outro lado, a Constituição de I89 I institui a laicidade, a gratuidade e a obrigatoriedade do ensino. Diretrizes importantes, mas que tiveram que enfrentar enormes dificuldades para serem implementadas tendo em vista o modelo federativo que descentralizava o ensino primário pelos estados.

Bonfim milita para que o ensino popular seja de fato implementado pela República, já que a sociedade moderna supunha alfabetização universal. A difusão do processo educacional se torna, assim, eixo central da moderniza- 
ção do Brasil. E para isso era fundamental a efetivação da responsabilidade do Estado na área educacional (Botelho, 2002). Os educadores defendem a escola e não mais a família como a instituição a ser responsável pelo ensino. Propunham que a escola deveria seguir padrões específicos de espaço, de métodos de ensino, de conteúdo curricular e de tipo de atividades pedagógicas. Até os equipamentos da sala de aula deveriam ser uniformizados, o mobiliário seria adequado ao tamanho da criança, a ventilação e a iluminação do ambiente deveriam seguir padrões e preceitos higiênicos. Todas essas normas se faziam presentes no que se entendia como uma educação republicana e os currículos deveriam exibir os cuidados com o corpo, com os gestos, com roupas e sapatos (uniformes) dos alunos (Gomes, 2002). A valorização do ensino levava à valorização do professor, daí a importância e o cuidado com as Escolas Normais responsáveis pela formação dos professores nos mais avançados métodos de ensino. O professor primário era considerado mesmo a chave da escola republicana.

Pois bem, a atuação de Manuel Bonfim toma forma dentro de tais premissas e é com elas que ele registra seu desconforto diante da situação de desconhecimento sobre as condições do ensino no país. Diz ele: "[...] O que não conheço é país onde o governo central se despreocupe, tão absolutamente, da instrução primária como entre nós; não sabendo se o povo aprende nem se há escolas, nem o que nelas se ensina" (Educação e Ensino, I/2, p. I42-I44 apud Bomeny, 2005: I I).

Se Bonfim se defrontou com Silvio Romero a propósito das interpretações do atraso brasileiro no livro A América Latina, ele vai se somar a outro importante crítico literário, José Veríssimo, que em I 890 publica o ensaio A educação brasileira em que defende a necessidade de reforma moral dos brasileiros, um programa de reforma do sistema escolar e dos currículos. Para José Veríssimo, o que une os povos e cria as nações são o sentimento do passado, o rico legado de tradições e o desejo de viver juntos. O ensino da história pátria torna-se então instrumento de uma educação cívica que é fundamental à modernização da sociedade e à criação da nação brasileiras. A proximidade entre Bonfim e Veríssimo também se acentua quando se registra a condenação que José Veríssimo faz das ciências morais e filosóficas ensinadas no Brasil - e que deu origem à cultura bacharelesca - como herança cultural negativa da Ibéria.

A descentralização do ensino pelas unidades da federação produziu um ensino diferenciado e precário que se expressava em altíssimas taxas de analfabetismo e em crianças em idade escolar que não frequentavam a escola. A consciência dessa situação leva, a partir dos anos I920, intelectuais e políticos a se unirem em um movimento chamado Escola Nova, que faz estudos e realiza experiências de reforma educacional em alguns estados como São Paulo, Minas Gerais, Pernambuco, Bahia e Distrito Federal. Anísio Teixeira, A. Carneiro Leão, Fernando de Azevedo e Lourenço Filho, entre outros, são os "intelectuais reformadores" do movimento de reforma do ensino primário e normal, e do 
"manifesto dos pioneiros da Educação Nova" que vai ser divulgado em I932 (Bomeny, 200I). Possivelmente, a idade e/ou a doença de Bonfim no fim de sua vida o impediram de fazer parte desta nova geração que está se organizando para mudar os rumos da educação no Brasil.

A militância dos educadores da "Escola Nova", entretanto, não deve ofuscar ou nos fazer negar o esforço dos educadores do início da República em sua luta pela reforma da educação primária, ainda que não tenham sido capazes de obter grande sucesso. Sabemos que a crítica à Primeira República a partir dos anos 1920 reúne matrizes político-ideológicas de variado teor, de Oliveira Vianna a Manuel Bonfim, passando pelos modernistas. Sabemos que os primeiros anos do século XX mereceram o epíteto de "República dos Conselheiros" ou de "República Velha" e foram marcados por seus intelectuais descrentes, desiludidos com o novo regime político. Ao sinalizar isso quero registrar que esse tempo enfrentou uma grande "batalha de memória" que o tornou pouco conhecido e reconhecido. Isso vem sendo alterado e a Primeira República está merecendo a atenção de historiadores, valendo citar, entre outros, o trabalho de Eliane Dutra sobre o Almanaque Brasileiro Garnier (2005). O Almanaque foi um instrumento pedagógico que buscou promover a nacionalidade brasileira, o regime republicano e inserir o Brasil na modernidade europeia. Assim, ainda que a educação entendida como ensino primário tenha merecido pouca ação e obtido resultados precários ou tenha tido pouco êxito no processo de modernizar o país, outros instrumentos de atuação se fizeram presentes.

A educação como a redenção do atraso, como viabilização da modernidade valoriza a escola primária, a instrução como indutora de virtudes públicas. Ao mesmo tempo se explicita uma controvérsia sobre o tipo de educação e de disciplinas que devem ser priorizadas na escola - as humanidades ou as científicas -, e que produzem bacharéis ou engenheiros. Até os modernistas de 1922 trataram indiretamente do tema da educação ao combater o chamado "lado doutor" da formação cultural brasileira. O lado opulento, decorativo, ornamental do ideário parnasiano estaria encarnado na figura do bacharel, o que explicita o anacronismo da educação brasileira de matriz jesuítico-bacharelesca (Botelho, 2002).

Após a publicação de seu primeiro livro, como já mencionamos, Manuel Bonfim escreveu livros de pedagogia e de psicologia, além de atuar em instituições voltadas ao ensino. Fez parte também da linhagem de autores que se dedicou a produzir textos para crianças, transmitindo lições de português, de história e de geografia, mas, acima de tudo, valores fundamentais de amor à nação brasileira. Nessa categoria Bonfim escreveu, junto com Olavo Bilac, um dos mais interessantes livros na categoria que hoje pode ser chamada de obra paradidática. Através do Brasil (narrativa) traz na capa a explicação: "Livro de leitura para o curso médio das Escolas Primárias" e "Livro de uso autorizado pelo Ministério da Educação", o que esclarece a recepção memorável e que 
garantiu ter tido 67 edições conhecidas até i962. A documentação da Editora Francisco Alves informa que o livro, impresso em Paris em igıo, teve tiragem de 4 mil exemplares e que, em I9I3, houve uma segunda edição (Lajolo, 2000).

Através do Brasil combina ficção e história e apresenta uma "jornada educativa" na qual as personagens se formam à medida que se ligam à coletividade. O livro transmite um tipo de catecismo cívico capaz de constituir um novo sentimento nacional para todos aqueles que estão sendo alfabetizados pela escola. Assim, tal livro pode ser considerado um exemplo muito bem-sucedido da literatura escolar nacional, um gênero que teve destaque nos primeiros anos da República.

Marisa Lajolo, consagrada pesquisadora de literatura infantil em geral e de Monteiro Lobato em particular, autora da Introdução à reedição de Através do Brasil pela Companhia das Letras em 2000, nos esclarece um pouco mais ao nos informar que o livro é uma espécie de "versão brasileira" de um best-seller escolar francês, La tour de la France par deux garçons, assim como de outro livro, Cuore, com a mesma função na Itália recém-unificada. E também nos lembra que, além de sua conhecida e reconhecida obra poética, Bilac foi também tradutor da obra de Wilhem Bush, intitulada no Brasil como Juca e Chico: história de dois meninos em sete travessuras. Para Mariza Lajolo, Através do Brasil está inscrito em duas matrizes fortes. Aquela do cânone da literatura infantil e didática e a do gênero da literatura de viagem herdeira do primeiro documento oficial de nossa descoberta, a Carta de Caminha.

É preciso registrar que Bilac e Bonfim se tornaram amigos desde a chegada deste último em I888 ao Rio. Bonfim passa a participar do círculo intelectual e boêmio de Bilac que frequentava redes de sociabilidade variadas como rodas literárias, redações de jornais, de revistas, cafés, confeitarias e livrarias da cidade. Bonfim e Bilac partilhavam da convicção do papel transformador da educação e estiveram presentes em instituições dedicadas à promoção da educação pública como Pedagogium, criada em I890, e a Secretaria de Instrução Pública do Distrito Federal. Bonfim foi diretor da Pedagogium de I897 a I 905 e de I9I I a I9I9. Criou a Revista Pedagógica e também a revista Educação e Ensino, o primeiro laboratório de psicologia experimental do Brasil. Foi diretor da Escola Normal e também diretor de Instrução Pública do Rio de Janeiro de I898 a I900. Criou escolas profissionais e técnicas.

Para além do que coube a cada um dos autores, ou seja, a divisão do trabalho entre os dois, Manuel Bonfim e Olavo Bilac foram, segundo André Botelho (2002), artífices de uma nova modalidade de narrativa inaugurada com Através de Brasil em I9ıo. Eles já tinham publicado em I899 o Livro de composição para o curso complementar das escolas primárias e, em I90 I, o Livro de leitura para o curso complementar das escolas primárias, ambos compilação de textos de outros autores. Olavo Bilac também se associará a Coelho Neto escrevendo A terra fluminense (I898), Contos pátrios (I904), Teatro infantil (I905) e A pátria brasileira (I909). 
No caso da produção conjunta - Olavo Bilac e Manuel Bonfim -, pode-se dizer que Bonfim também ficou em uma posição subalterna, ficou esquecido ou foi apagado, neste caso, pelo tamanho e prestígio de seu parceiro. Olavo Bilac, escolhido de modo consagrador "príncipe dos poetas brasileiros" em concurso promovido pela revista Fon-Fon, em I9I3, é um dos autores que reafirmam suas ligações com o mundo latino e português. Poeta com amplo reconhecimento como representante da belle époque, como defensor da herança portuguesa e latina que nos unia à França por ocasião da Primeira Guerra Mundial, Bilac vai se colocar como missão a difusão do ensino primário, a expansão do ensino profissionalizante e a defesa do serviço militar obrigatório. Bilac, de "príncipe dos poetas" se torna "operário da nação" ao se engajar em campanhas cívicas pela instrução primária e mais tarde pelo serviço militar obrigatório e pela criação da Liga de Defesa Nacional. O alto prestígio de Bilac faz sombra sobre Bonfim e, depois, o desprestígio de Bilac como exemplo máximo da poesia parnasiana tão combatida pelos poetas modernistas dificulta qualquer recuperação de Bonfim.

Tanto Manuel Bonfim quanto Olavo Bilac entendiam e defendiam a educação como redenção do atraso. Eles estão preocupados e ocupados com a reforma moral da sociedade, com a construção da nação e com a formação dos portadores sociais do projeto de modernização. Ao definir assim seu trabalho, acabam por definir uma identidade social dos intelectuais no Brasil (Botelho. 2002).

Mas não foi só isso. Manuel Bonfim esteve ligado à fundação e à direção da revista $O$ Tico-Tico, criada pelo empresário e deputado mineiro Luiz Bartolomeu de Souza Silva (I866-I932). Luiz Bartolomeu também fundou e dirigiu outras publicações como as revistas O Malho e Ilustração Brasileira.

O Tico-Tico, revista semanal cujo primeiro número circulou em I905, chegou no ano seguinte a uma tiragem de Ioo mil exemplares por semana. Ângelo Agostini desenhou o logotipo da revista onde crianças nuas brincam com as letras. J. Carlos também se fazia presente na revista. E o que apresentava? Passatempos, mapas educativos, literatura juvenil, informações sobre história, geografia, ciências, artes e civismo. Suas seções eram: "Por que me orgulho de ser brasileiro", "Quadros de nossa história”, "Decálogo de deveres”, "Gavetinha do saber", "Museu escolar", entre outras. O Tico-Tico apresenta também jogos de armar e heróis nacionais que povoam as mentes de crianças e jovens, lendas e personagens do folclore regional e popular, cantigas e contos. E mais. Apresentava história em quadrinhos para um público infantil, entre elas a turma Reco-Reco, Bolão e Azeitona, desenhados por Luiz Sá. Em depoimentos em que falam sobre suas infâncias, Dorival Caymmi, Érico Veríssimo, Carlos Drummond de Andrade, Lígia Fagundes Telles, José Lins do Rego, Jorge Amado e Câmara Cascudo mencionam que tiveram contato com o mundo da fantasia e das letras, tiveram noções de cidadania e de patriotismo lendo a revista O Tico-Tico (Gonçalo Jr., 2005). 
Assim, revistas como O Malho e O Tico-Tico, o Almanaque d'O Malho e o Almanaque Brasileiro Garnier, entre outras, tiveram papel fundamental no sentido de ensinar princípios de civilidade e de cidadania para uma população que se queria moderna e civilizada. Esses foram, na ausência de um sistema escolar abrangente, por assim dizer, instrumentos de uma cultura de massa na Primeira República.

Além de ter dirigido a revista $O$ Tico-Tico, Bonfim exerceu cargos públicos ligados à atividade educacional no Rio de Janeiro. Sua inserção no campo educacional o fez participar do Conselho Superior de Instrução Pública e ser relator de concurso para escolha do livro de história da América a ser adotado nas escolas de formação de professores. Assim vai avaliar a obra A história da América (I899), de Rocha Pombo, cujos males são apresentados como resultado do passado colonial funesto. Este autor, assim como o historiador português Oliveira Martins, em sua História de Portugal (1879), fala da decadência ibérica. Passado colonial funesto e decadência ibérica são marcas de visão historiográfica de Bonfim. O autor, para falar sobre o parasitismo ibérico, lança mão principalmente do relato de Oliveira Martins sobre o caráter predatório da colonização portuguesa. Para ele, o conservadorismo das oligarquias ibéricas é fruto do parasitismo. Tudo isso faz o Estado se tornar "órgão de opressão" a serviço da elite. Estes temas e tais influências vão reforçar sua interpretação sobre o país e vão se fazer presentes no livro o Brasil na história, cuja primeira edição é de I930 (Gontijo, 2003).

\section{A TRILOGIA SOBRE O BRASIL}

Quer seja nesse livro anteriormente citado, assim como em O Brasil nação, Bonfim interpreta a história do Brasil como cindida entre duas forças, duas tradições: uma que expressa, desde o século XVII, a alma brasileira republicana e democrática - a verdadeira nação; outra ligada à monarquia portuguesa que domina o Estado que explora e oprime a nação. A historiografia também se divide em duas correntes: a oficial, bragantina, antipatriótica, portuguesa, e a outra, patriótica, republicana, revolucionária, brasileira. A primeira tem Varnhagen como um de seus expoentes; Capistrano de Abreu seria um representante da segunda e acabaria se tornando o "patrono" de uma suposta história social. O poder bragantino vai se colocar contra o povo que se unificou cedo e criou o espírito nacional, uma unidade profunda. As revoluções frustradas (a Independência, a Abdicação, a Abolição e a República) marcam a permanência da opressão do poder bragantino que também forma a mentalidade das elites dirigentes e dos intelectuais em sua cópia do pensamento europeu. O que caracteriza sua visão da história do Brasil, segundo Reis (2006), é que para ele os verdadeiros heróis são os derrotados, enquanto os poderosos são os bandidos. 
Vale ressaltar que aqui já estamos em outro momento histórico, quando Bonfim vai publicar três livros que o fazem entrar no panteão de intelectuais brasileiros: O Brasil na América Latina: caracterização da formação brasileira (I 929); O Brasil na história: deturpação dos trabalhos, degradação política (I930) e O Brasil nação: realidade da soberania brasileira (I93I). Tais obras foram publicadas pela Editora Francisco Alves.

Neste terceiro momento o contexto já é outro, estamos no final dos anos I920 e início dos anos I930. No primeiro livro, O Brasil na América Latina, ele retorna ao tema do livro A América Latina, agora com olhar mais focado no Brasil; no segundo, O Brasil na história, ele disserta sobre a história escrita sobre o Brasil mesmo sem fazer parte do "pequeno mundo dos historiadores" (Gontijo, 2003); e, por fim, O Brasil nação (I93I) vai se centrar mais na conjuntura da República no século XX.

Vale lembrar que, nos anos I930, no bojo da Revolução, tem-se o surgimento de novas editoras que abrem espaço para discutir, interpretar, publicar livros que mais uma vez querem decifrar os males do país. Vale citar Alcindo Sodré, com A gênese da desordem; Martins de Almeida, com Brasil errado: ensaio político sobre os erros do Brasil como país; e Virgínio Santa Rosa, com A desordem: ensaio de interpretação do momento e $O$ sentido do tenentismo. Tais livros foram publicados entre I930 e I932, editados pela Editora Schmidt, compondo a chamada Coleção Azul. Para mencionar outros autores daquela época dentro do mesmo espírito, vale citar Vivaldo Coaraci, Problemas nacionais (I930); Hermes Lima, Problemas do nosso tempo (I935), e Azevedo Amaral, Ensaios brasileiros (I930).

Assim, quando Bonfim publica a sua trilogia em I929, I930 e em I932, vários outros autores também estão produzindo obras sobre os males do Brasil e propondo soluções para enfrentar os problemas nacionais.

A influência do pensamento de Manuel Bonfim, por exemplo, sobre Azevedo Amaral pode ser percebida em diferentes temas e análises. José Antonio Azevedo Amaral também faz uma releitura da história brasileira e dos impasses a serem enfrentados. Em seu livro Estado autoritário e a realidade nacional, de I938, ele apresenta uma crítica ao Império e ao seu parlamentarismo, totalmente inaplicáveis às condições brasileiras. Diferentemente de vários autores dos anos I930, ele não vê o Império como um modelo de centralismo a ser imitado. O império se caracteriza, não pelo centralismo, mas pelo controle do mando por uma classe parasitária (prenúncio das análises sobre o controle do estamento burocrático como em Raymundo Faoro?). Azevedo Amaral também assumiu uma perspectiva evolucionista, lançando mão de um certo modelo de interpretação da sociedade como organismo (Oliveira, I982). E ele também padeceu de certo esquecimento ou discriminação na medida em que foi um dos importantes ideólogos do Estado Novo.

Vale lembrar que será Azevedo Amaral quem escreve o "prefácio" da segunda edição de A América Latina: males de origem (Rio de Janeiro: A Noite, s/d). 
A terceira edição de A América Latina: males de origem (Rio de Janeiro: Topbooks, I993) tem apresentação de Darcy Ribeiro e de Franklin de Oliveira e ali também é republicado o prefácio da segunda edição, de autoria de Azevedo Amaral.

A perspectiva nacionalista do nosso autor foi ressaltada nos anos 1930. Ela teria feito Manoel Bonfim ser reverenciado e lido, como pode ser reconhecido no livro de Bonfim O Brasil, organizado em I 935 por Carlos Maul e que integrou a Coleção Brasiliana, número 47. Fazer parte de tão importante coleção não é trivial, não significa exatamente estar esquecido, contudo a percepção de esquecimento teve continuidade. O que teria contribuído para isso? Temos então que olhar para a posição de Maul, jornalista como tantos outros intelectuais da época que garantiam sua subsistência na imprensa. Mas outros jornalistas conseguem galgar posições mais altas, alcançar postos em instituições de maior prestígio tais como o Instituto Histórico Geográfico Brasileiro (IHGB), a Academia Brasileira de Letras (ABL), ter seus livros publicados por casas editoras como a Francisco Alves, a José Olympio, a Editora Nacional. Não é o caso de Maul, que poucos conhecem ou sabem quem foi.

Carlos Maul (I887-I974), jornalista, redator de jornais da capital federal e literato, tem curta atuação na política em I930 quando se elegeu deputado estadual no Estado do Rio de Janeiro, fazendo parte de um dos grupos descendentes da liderança de Nilo Peçanha. Em I 937 integrou comissão responsável pelas publicações da Biblioteca do Exército. Foi membro das academias carioca, fluminense e petropolitana de letras e publicou cerca de 60 livros.

Ou seja, pode ser classificado como "intelectual de província", ainda que circule na capital federal. É Maul quem escreve a "Nota Introdutória" do livro O Brasil, volume 47, que integra a famosa Coleção Brasiliana. Ali ele nomeia Manuel Bonfim como "mestre". E esclarece: Bonfim tinha programado fazer uma obra de síntese, de divulgação de suas ideias, para mostrar o que fomos e o que somos como parcela da humanidade. Esta reunião estaria presente no volume agora publicado onde ele (Maul) teria sintetizado o fundamental na trilogia já editada.

O livro expõe seu pensamento e conceitos sobre o Brasil, a organização da sociedade, a expansão econômica, a vida política do Brasil Colônia, Império e República até i930 e fala do futuro do país tendo em vista as reformas sociais em curso no mundo e que influenciam o Brasil. Bonfim fez revisão de nossa história e principalmente expôs as bases do estudo para o conhecimento da constituição da nacionalidade. Ressalta Maul, Bonfim fez a defesa da atividade de nossa gente, das virtudes do indígena e do preto, das vantagens do cruzamento do lusitano com eles para alcançar o grau de civilização. A longa doença impediu Bonfim de realizar o sonho de divulgar suas análises, entretanto sua vontade pôde ser realizada.

Foi Maul quem selecionou e reuniu nesse volume o que seria fundamental na trilogia mantendo as próprias palavras (sem o peso das citações) 
de Manuel Bonfim. Ao adotar uma seleção e justaposição de textos a partir das três obras, sem fazer referência à fonte dos trechos selecionados, Maul acaba por esvaziar seu propósito. Afinal, pode-se perguntar, o livro é mesmo de autoria de Manuel Bonfim ou uma leitura de Carlos Maul sobre Manuel Bonfim? O questionamento a tal procedimento foi apresentado pela primeira vez por Süssekind e Ventura em seu livro de I984, que, ao contrário do de Maul, transcreve integralmente partes de capítulos dos livros de Bonfim, assim como as notas do texto original informando qual a fonte e as páginas originais, obedecendo aos procedimentos que a norma acadêmica prescreve. O livro O Brasil inclusive não costuma ser listado entre as obras de Manuel Bonfim, nem entre as obras de Carlos Maul, ficando assim em uma espécie de limbo de autoria.

O historiador José Carlos Reis (2006), ao contrário, vai dizer que Bonfim se tornou mais popular com a publicação da coletânea O Brasil, contrariando a visão de Süssekind e Ventura (I984) e de Aguiar (2000). Em sua análise, diz que vai fazer uso do livro O Brasil como sua principal fonte, já que a obra organizada por Maul teria contribuído muito para a popularização de Bonfim. Considera mesmo que as resistências à coleção de Maul nada mais seriam do que um "pedantismo acadêmico". Considera que Maul, admirador de Bonfim, foi fiel ao autor e o tornou mais acessível.

Reis considera, entretanto, que a seleção realizada por Maul teria ressaltado Bonfim como defensor de um "nacionalismo fascista", integralista, enquanto outras leituras o veriam mais como socialista. Nessa linha, Bonfim é visto como um marxista brasileiro precoce, original, anterior à própria criação do Partido Comunista do Brasil (PCB) em I922. Aguiar, seu biógrafo, o veria como um anarquista socialista tendo em vista suas leituras de Proudhon, Bakunin e Kropotkin. Cada um retira de seus livros trechos que podem ser interpretados de um modo ou de outro. Seu nacionalismo foi, assim, recuperado à direita e à esquerda.

Vale lembrar que nos anos igro, i920 e i930 o nacionalismo estava mais próximo a movimentos de direita já que o socialismo à época era uma bandeira internacionalista. Assim, o nacionalismo de Bonfim foi recuperado originalmente à direita e só mais tarde à esquerda. É que

o tema da nação não estava presente na ideologia marxista original. o processo de incorporação da questão nacional pelo movimento comunista tem a ver com a chamada implantação do socialismo num só país e as condições que se estabeleceram à época. [...] $\mathrm{O}$ tema do nacionalismo trouxe para o interior do movimento socialista uma valorização muito grande da dimensão do Estado (Vianna, 2005: 209-2 Io).

Para além das diversas leituras interpretativas, Reis vai reforçar as razões para se ler Manuel Bonfim. Ele nos ensinou a recusar o "olhar dominado" que nos caracteriza; foi contra teorias raciológicas; pensou o Brasil no contexto latino-americano; combateu a história oficial; denunciou a destruição do meio ambiente (que não era tema presente à época). Se ele tem todas essas qualidades, é preciso voltar à pergunta inicial: por que foi tão esquecido? 
Segundo Reis, o texto de Bonfim é prenhe de emoção e intuição, a sua linguagem é passional, furiosa mesmo, e a redundância de sua argumentação acaba fazendo o discurso perder o rigor. Além desses problemas relativos à sua retórica, Reis vai apontar outra questão de ordem política: seu discurso não tinha destinatário. Se o remédio para a formação do povo brasileiro dependia de uma educação popular, esta só seria capaz de ser implementada por um novo Estado, então era preciso instaurar uma nova ordem política. E para tal era preciso um movimento revolucionário vindo de baixo. E quem seria o sujeito revolucionário, o protagonista social capaz de fazer tal mudança? Ainda segundo Reis, o exemplo mais próximo a ser seguido seria o modelo da revolução mexicana (I9IO-I9I7) já que Manuel Bonfim não reconhecia valor no modelo de Partido proposto pelas internacionais comunistas. Aqui também Bonfim se manteve como um rebelde solitário!

Avançando em outra explicação, que não pretende se contrapor às anteriores e sim se somar a elas, gostaria de chamar a atenção para outro dado. Para tentar entender os altos e muitos baixos na recepção do autor, é possível registrar o longo espaço de tempo no qual ele produz e é publicado. Seu livro primeiro é editado em I905. Seus últimos três livros foram publicados em I929, I930 e I93 I. Sobre o livro de I935, o de Carlos Maul, paira uma dúvida de autoria... Manuel Bonfim ainda teria outro livro, Cultura e educação do povo brasileiro, obra que teria sido ditada a Joracy Camargo, que, publicada após sua morte, foi premiada pela Academia Brasileira de Letras em I933. Ou seja, ele pode ser caracterizado como autor de grande longevidade, publicando em um espaço de tempo de cerca de 30 anos. Como já mencionamos, entre a publicação do primeiro e dos três últimos livros aqui mencionados ele publica livros sobre pedagogia, psicologia e sobre a importância da educação popular, além do livro de literatura infantil e didática.

Os autores que publicam em torno de I 900 não são os que estão publicando em torno de i930. Para relembrar: Manuel Bonfim nasce em I868, morre em I932. Entre seus contemporâneos de publicação, ou seja, que estão escrevendo e publicando em torno de I900, estão: Eduardo Prado (I860-I90I); Silvio Romero (I85I-I9I4); Alberto Torres (I865-I9I7); Euclides da Cunha (I866-I 909); Nina Rodrigues (I862-I906). Ou seja, a maioria deles não sobreviveu à Primeira Guerra nem acompanhou as transformações dos anos I920. Os autores que estão escrevendo e publicando em torno de I930 são de uma geração mais nova, vale citar como exemplos: Azevedo Amaral (I88I-I942), Oliveira Vianna (I883-I95I) e Roquette-Pinto (I884-I954). O mesmo pode ser dito dos intelectuais voltados para a educação. Bonfim faz parte dos que estão militando no campo no início da República, não faz parte do movimento da Escola Nova.

Este texto busca ressaltar o quanto a leitura de um autor segue não só atributos referentes ao conteúdo de seus livros (suas qualidades internas), mas também a certas variáveis externas relativas aos pares que recebem a 
obra, que fazem sua crítica positiva ou negativa, que a divulgam. Os contextos político, histórico e cultural também interferem na recepção de uma obra.

Na década de I930 são publicados dois livros de autores que irão marcar profundamente, a partir de então, as interpretações do Brasil até hoje. Casa-grande \& senzala (1933), de Gilberto Freyre, e Raízes do Brasil (1936), de Sérgio Buarque de Holanda. Diante dessas duas obras e figuras exponenciais, muitos autores foram deixados de lado.

Por outro lado, há pontos semelhantes entre vários intérpretes do Brasil. Cabe registrar que em Oliveira Vianna, em Manuel Bonfim, em Gilberto Freyre e em Sérgio Buarque as explicações sobre o Brasil do século XX vão ser buscadas no Brasil Colônia, a chamada América Portuguesa. Os males ou os traços característicos do país, a cultura coletiva que teria brotado da casa-grande ou do latifúndio, a personalidade coletiva lida como "cordialidade", o clientelismo, tudo isso teria derivado do tipo de colonização. Esse mergulho na história colonial funcionaria no Brasil da mesma forma como o retorno à Idade Média para a historiografia europeia.

\section{RECAPITULANDO...}

Os pontos centrais que ressaltamos: Manuel Bonfim fez parte da geração de médicos chamados "missionários do progresso", ocupados com a salvação do país, embora discordasse da vertente hegemônica dessa época. Foi um dos que recusou a vertente racialista de explicação dos males do Brasil. Defendeu as qualidades do povo mestiço no início do século XX, bem antes da obra de Gilberto Freyre nos anos I930. Foi antiamericano quando os Estados Unidos se apresentavam como alternativa à dominação europeia e ressaltou a semelhança do Brasil com os demais países da América Latina, quando historiadores procuravam diferenciar o Brasil das "republiquetas" latino-americanas. Fez uso da categoria de "parasitismo" para dar conta dos males da colonização. Ser contra a corrente tem um custo (ser desacatado por Silvio Romero) que Bonfim aceitou pagar ou teve que enfrentar! Segundo Aguiar (2000), Manuel Bonfim se manteve afastado, teve um distanciamento crítico em relação a instituições do campo intelectual de seu tempo. Rejeitou até mesmo o convite de Machado de Assis para ser um dos fundadores da ABL. Andava, por assim dizer, na contramão das tendências do seu tempo. Foi afastado ou se manteve afastado?

Passou a se engajar no campo educacional participando tanto da burocracia de Estado quanto escrevendo obras sobre pedagogia e psicologia. Escreveu também um livro com Olavo Bilac, de divulgação para crianças de suas ideias sobre o Brasil e, nesse caso, acabou sendo apagado pela imensa visibilidade de seu parceiro. Participa da criação e dirige a revista O Tico-Tico, tipo de empreendimento que demorou muito a ser reconhecido pelo mundo intelectual e acadêmico. 
Escreve livros que sintetizam suas ideias e expressam sua erudição na virada da década de I930. Aqui a figura que está escrevendo na mesma época e pode ser considerada seu "seguidor" é Azevedo Amaral (que, como já foi mencionado, escreveu o prefácio da segunda edição de A América Latina: males de origem, s.d: VII-XIII), autor também "esquecido" pela geração que vai explicar o Brasil a partir de Gilberto Freyre e de Sérgio Buarque de Holanda.

Pode-se pensar em diferentes linhagens de recuperação de Manuel Bonfim: a da crítica literária, que tem Silviano Santiago, Flora Süssekind e Roberto Ventura como expoentes; a da antropologia interpretativa da América Latina que teve Darcy Ribeiro como figura máxima; e, por fim, a linhagem sociológica que ganha visibilidade a partir do livro de Aluísio Alves Filho e que também se fez presente em Octavio Ianni e André Botelho. É nesta última que se encontram aqueles que vão lembrar e valorizar a participação de Bonfim em atividades ligadas à educação popular. Sua integração ao grupo que, sob a liderança de Elysio de Carvalho, cria, em I904, a Universidade Popular de Ensino Livre ligada ao Partido Operário Independente, com intelectuais como Evaristo de Moraes, Fábio Luz, Felisberto Freire, José Veríssimo, Pedro Couto e Rocha Pombo. Entre esses intelectuais de esquerda no início do século XX está, por exemplo, Antonio Evaristo de Moraes (I87 I-I939), que em I89o participou da criação do Partido Operário, primeira organização de caráter socialista no Brasil. Em 1902 funda também o Partido Socialista, que se filia a uma internacional socialista. Evaristo de Moraes foi também cofundador da ABI em I908; em I9Io defendeu os marinheiros rebelados na Revolta da Chibata sendo advogado de João Cândido. Especializou-se na defesa dos trabalhadores, o que o fez participar do Ministério do Trabalho no governo Vargas e colaborar na elaboração das Leis do Trabalho na década de i930.

Essa militância socialista a favor do povo ou do operariado, que acontece antes da existência de um partido comunista no Brasil, também não costuma ser muito lembrada e, principalmente, valorizada. Bonfim está mencionado na História das ideias socialistas no Brasil, de Vamireh Chacon (I965), mas, como já foi mencionado, até essa data ainda não tinha conseguido ser incorporado ao panteão de autores nacionais.

E a relação de Caio Prado Júnior com Bonfim? Pode-se dizer que o seu "sentido da colonização" compartilha com Bonfim a ideia do peso da colonização sobre o rumo a ser trilhado pelo Brasil depois da dita independência. Por outro lado, podemos imaginar que Caio Prado Júnior também não se sinta confortável quando se defronta com o uso, por parte de Bonfim, da categoria "parasita" e do conceito de "parasitismo" que migra do campo biológico para o social.

Foi necessário que outras vozes nos anos I980 começassem a reler o pensamento social no Brasil e recuperassem a originalidade das análises de Manuel Bonfim, valorizassem o pioneirismo de sua argumentação, principal- 
mente no livro publicado no início do século XX no qual ele recusa a explicação racialista e se apresenta como um precursor de um nacionalismo "materialista". O papel dos críticos literários Flora Süssekind e Roberto Ventura foi fundamental, já que não partiam para uma defesa ideológica do autor e sim para a valorização de seus argumentos analíticos vis-à-vis os contemporâneos de Bonfim. Esse processo só pôde avançar quando se tornou possível ter acesso facilitado aos textos do autor. E isso só aconteceu quando suas obras foram reeditadas a partir de 1993 pela Editora Topbooks.

Em junho de 2013, ao ver os diferentes comentários a respeitos dos movimentos das ruas no Brasil, encontrei uma entrevista com o sociólogo catalão Manuel Castells na qual ele fala dos políticos como "burocratas preguiçosos" e menciona a rápida circulação das mensagens nas redes sociais como "distribuição viral". Se traduzirmos "burocratas preguiçosos" por "parasitas" e considerarmos o uso da categoria "vírus", veremos que, ontem e hoje, o mundo biológico, bactérias e/ou vírus, assim como a genética, são centrais como modelos científicos ou como metáforas em nossa forma de explicar o mundo, inclusive o social.

Recebido em I I/03/20I5 | Aprovado em I4/o9/20I5

Lucia Lippi Oliveira é doutora em Sociologia pela Universidade de São Paulo (USP). Atualmente, é professora associada do Programa de Pós-Graduação em História, Política e Bens Culturais do CPDOC/FGV-RJ. Realizou pesquisas no campo de pensamento social no Brasil e sobre as origens da sociologia no Rio de Janeiro. Pesquisou sobre o papel da fronteira na construção da identidade nacional no Brasil e nos Estados Unidos e estudou as relações entre a cultura nacional e a cultura dos imigrantes. Dedica-se a desenvolver projetos sobre patrimônio, cultura e identidade regional. Foi bolsista da Capes/Fulbright para pós-doutoramento na Brown University em I993-I994, foi coeditora da revista Estudos Históricos do CPDOC e tem bolsa de produtividade em pesquisa do CNPq. 


\section{NOTAS}

I Cabe desde já uma primeira observação sobre a grafia do seu nome. Os textos mais antigos conservam a grafia original, os mais recentes a atualizam e aparece como Manuel Bonfim, outros ainda Manuel Bomfim. Vou atualizar a grafia.

\section{REFERÊNCIAS BIBLIOGRÁFICAS}

Aguiar, Ronaldo Conde. (2000). O rebelde esquecido: tempo, vida e obra de Manoel Bomfim. Rio de Janeiro: Topbooks.

Aguiar, Ronaldo Conde. (2000). Manuel Bonfim. In: Pequena bibliografia crítica do pensamento social brasileiro. Brasília/ São Paulo: Paralelo/Marco Zero, p. I53-I6r.

Aguiar, Ronaldo Conde. (I996). Um livro admirável. In: Bonfim, Manuel. O Brasil nação: realidade da soberania brasileira. 2.ed. Rio de Janeiro: Topbooks, p. 22-34.

Alves Filho, Aluizio. (1979). Pensamento político no Brasil: Manoel Bomfim, um ensaísta esquecido. Rio de Janeiro: Achiamé/ Socii.

Bomeny, Helena. (200I). Os intelectuais da educação. Rio de Janeiro: Zahar.

Bonfim, Manuel. (s.d.). A América Latina: males de origem. 2.ed. Prefácio de Azevedo Amaral. Rio de Janeiro: A Noite. Bonfim, Manuel (1997). O Brasil na América: caracterização da formação brasileira. 2.ed. Prefácio de Maria Thétis Nunes. Rio de Janeiro: Topbooks.

Bonfim, Manuel (I996). O Brasil nação: realidade da soberania brasileira. 2.ed. Prefácios de Wilson Martins e de Ronaldo Conde Aguiar. Rio de Janeiro: Topbooks.

Bonfim, Manuel (I993). A América Latina: males de origem. 3.ed. Prefácios de Darcy Ribeiro e de Franklin de Oliveira. Rio de Janeiro: Topbooks.

Bonfim, Manuel. (I93I). O Brasil nação: realidade da soberania brasileira. Rio de Janeiro: Francisco Alves.

Bonfim, Manuel (I930). O Brasil na história: deturpação dos trabalhos, degradação política. Rio de Janeiro: Francisco Alves. Bonfim, Manuel. (I 929). O Brasil na América: caracterização da formação brasileira. Rio de Janeiro: Francisco Alves. 
Bonfim, Manuel. (s.d.) [1905]. A América Latina: males de origem. Rio de Janeiro/ Paris: Garnier.

Bonfim, Manuel \& Bilac, Olavo. (I9Io). Através do Brasil. Rio de Janeiro: Francisco Alves. (Teve 67 reedições, sendo a última pela Companhia das Letras, 2000. Com Introdução de Mariza Lajolo).

Botelho, André. (2009). Manoel Bomfim: um percurso da cidadania no Brasil. In: Botelho, André \& Schwarcz, Lilia M. (orgs.). Um enigma chamado Brasil. São Paulo: Companhia das Letras, p. II8-I3I.

Botelho, André. (2002). Aprendizado do Brasil: a nação em busca dos seus portadores sociais. Campinas: Ed. Unicamp.

Candido, Antonio. (I988) [I963]. O método crítico de Silvio Romero. São Paulo: Edusp.

Chacon, Vamireh. (I965). História das ideias socialistas no Brasil. Rio de Janeiro: Civilização Brasileira, p. 356-362.

Corrêa, Mariza. (200I). As ilusões da liberdade: a Escola Nina Rodrigues e a antropologia no Brasil. 2.ed. Bragança Paulista: Edusf.

Dutra, Eliane de Freitas. (2005). Rebeldes literários da República: história e identidade nacional no Almanaque Brasileiro Garnier (I903-I9I4). Belo Horizonte: Ed. UFMG.

Filgueira, André Luiz de Souza. (2012). A utopia nacionalista de Manoel Bomfim. Em Tempo de História, 20, p. I53-163. Gomes, Angela de Castro. (2002). A escola republicana: entre luzes e sombras. In: Gomes, Angela de Castro; Pandolfi, Dulce Chaves \& Alberti, Verena (orgs.). A República no Brasil. Rio de Janeiro: Nova Fronteira/CPDOC, p. 385-450.

Gonçalo Junior. (2005). Paixão infantil. Revista Nossa História, 2/24, p. 52-55.

Gontijo, Rebeca. (2003). Manuel Bonfim, "pensador da história" na Primeira República. Revista Brasileira de História, 23/45, p. I 29-I 54 .

Herschmann, Micael. (I996). Entre a insalubridade e a ignorância: a construção do campo médico e do ideário moderno no Brasil. In: Kropf, Simone; Herschmann, Micael \& Nunes, Clarice (orgs.). Missionários do progresso. Rio de Janeiro: Diadorim, p. I I-67. 
Lajolo, Marisa. (2000). Introdução. In: Bonfim, Manuel. Através do Brasil. São Paulo: Companhia das Letras, p. I I-32. Lima, Nísia Trindade \& Sá, Dominichi Miranda de. (2008). Roquette-Pinto e sua geração na república das letras e da ciência. In: Lima, Nísia Trindade \& Sá, Dominichi Miranda de (orgs.). Antropologia brasiliana: ciência e educação na obra de Edgard Roquette-Pinto. Belo Horizonte/Rio de Janeiro: Ed. UFMG/Fiocruz, p. 57-84.

Martins, Wilson. (I996). Profeta da quinta revolução. In: Bonfim, Manuel. O Brasil nação: realidade da soberania brasileira. 2.ed. Rio de Janeiro: Topbooks, p. I3-2 I.

Nunes, Maria Thétis. (I 997). Manoel Bomfim: pioneiro de uma ideologia nacional. In: Bonfim, Manuel. O Brasil na América: caracterização da formação brasileira. 2.ed. Rio de Janeiro: Topbooks, p. I3-25.

Oliveira, Franklin de. (1993). Manuel Bonfim, o nascimento de uma nação. In: Bonfim, Manuel. A América Latina: os males de origem. 3.ed. Rio de Janeiro: Topbooks, p. 2I-28.

Oliveira, Lucia Lippi. (I999). A ilusão americana. In: Mota, Lourenço Dantas (org.). Introdução ao Brasil: um banquete no trópico. São Paulo: Senac, p. I35-I50 (Vol. 2).

Oliveira, Lucia Lippi. (I993). Uma leitura das leituras de Oliveira Vianna. In: Bastos, Elide Rugai \& Moraes, João Quartim de (orgs.). O pensamento de Oliveira Vianna. Campinas: Ed. Unicamp, p. 24I-27I.

Oliveira, Lucia Lippi. (I990). A questão nacional na Primeira República. São Paulo: Brasiliense.

Oliveira, Lucia Lippi. (I982). Autoridade e política: o pensamento de Azevedo Amaral. In: Oliveira, Lucia Lippi; Velloso, Mônica Pimenta \& Gomes, Angela Maria de Castro (orgs.). Estado Novo: ideologia e poder. Rio de Janeiro: Zahar, p. 4870.

Reis, José Carlos. (2006). Civilização brasileira e otimismo revolucionário (ingênuo): Manuel Bonfim e o sonho da República soberana e democrática. In: As identidades do Brasil 2. De Calmon a Bomfim: a favor do Brasil: direita ou esquerda? Rio de Janeiro: Ed. FGV, p. I83-23I.

Ribeiro, Darcy. (I993). Manuel Bonfim, antropólogo. In: Bonfim, Manuel. A América Latina: males de origem. 3.ed. 
Rio de Janeiro: Topbooks, p. 9-20. [Publicado originalmente na Revista do Brasil, I/2, I984, p. 48-59].

Schwarcz, Lilia M. (I993). As faculdades de medicina ou como sanar um país doente. In: O espetáculo das raças. São Paulo: Companhia das Letras, p. I89-238.

Süssekind, Flora. (2000). A América Latina: males de origem. In: Santiago, Silviano (org.). Intérpretes do Brasil. Rio de Janeiro: Nova Aguilar, p. 609-625.

Süssekind, Flora \& Ventura, Roberto. (1984). História e dependência: cultura e sociedade em Manuel Bonfim. São Paulo: Moderna.

Ventura, Roberto. (200I). Manoel Bomfim. A América Latina: males de origem. In: Mota, Lourenço Dantas (org.). Introdução ao Brasil: um banquete no trópico 2. São Paulo: Senac, p. 237-258.

Vianna, Luiz Werneck. (2005). Entrevista. In: Sento-Sé, João Trajano \& Paiva, Vanilda (orgs.). Pensamento social brasileiro. São Paulo: Cortez, p. 209-223. 
Palavras-chave

Manuel Bonfim; Interpretação do Brasil;

Antilusitanismo; Ensino da história para criança; Recepção da obra;

Keywords

Manuel Bonfim; Interpretations of Brazil;

Anti-Lusitanism; Historical education for children;

Reception.
MANUEL BONFIM: AUTOR ESQUECIDO OU FORA DO TEMPO?

\section{Resumo}

O artigo analisa a recepção da obra de Manuel Bonfim circunscrevendo-a no tempo e no espaço. Para fazer isso, acompanho como Manuel Bonfim tem sido lido desde o lançamento de seu primeiro livro em I905 e procuro entender os momentos de esquecimento e de reconhecimento de seu pensamento. A postura nacionalista do autor, sua análise sobre a América Latina, sobre o parasitismo ibérico, a defesa do ensino da história pátria são capítulos da trajetória de Bonfim. Para entender o sucesso ou o esquecimento de um autor ou de uma obra deve-se atentar à sua recepção para além do possível valor intrínseco de seu conteúdo. Assim, a aceitação ou o reconhecimento de um autor depende não só das qualidades de suas ideias e de seu texto, mas também de variáveis relacionadas ao campo intelectual existente e do qual o autor faz parte.

\section{MANUEL BONFIM: A WRITER OUT OF MIND} OR OUT OF TIME?

\section{Abstract}

The article analyses the reception of the work of Manuel Bonfim, circumscribing it in time and space. I follow the readings of Manuel Bonfim's works since his first book was published in I905, and I seek to understand the periods in which his work was either forgotten or remembered. His nationalist posture, his analysis of Latin America, of Iberian parasitism, the defence of teaching national history - all of these are chapters in the career of Bonfim. In order to understand the success or neglect of an author or work, we must look beyond intrinsic value and pay attention to reception. The acceptance or recognition of an author thus depends not only on the quality of his or her ideas and of his texts, but also on variables related to the prevailing intellectual field in which the author is implicated. 